\title{
Primary Breeding Ratio Analysis of an Improved Supercritical Water Cooled Fast Reactor
}

\author{
Zijing Liu ${ }^{1,2 *}$, Jinsen Xie ${ }^{1,2}$, Lihua He ${ }^{1}$ \\ ${ }^{1}$ Department of Nuclear Science and Technology, University of South China, Hengyang, China \\ ${ }^{2}$ China Institute of Atomic Energy, Beijing, China \\ Email: ${ }^{*}$ liuzijing1123@163.com
}

Received 17 September 2015; accepted 25 October 2015; published 28 October 2015

Copyright (C) 2015 by authors and Scientific Research Publishing Inc.

This work is licensed under the Creative Commons Attribution International License (CC BY).

http://creativecommons.org/licenses/by/4.0/

\section{c) (i) Open Access}

\section{Abstract}

The purpose of the study is to analyze the breeding ratio of a supercritical water cooled fast reactor (SCFR) and to increase the breeding core of SCFR. The sensitivities of assembly parameters, core arrangements and fuel nuclide components to the breeding ratio are analyzed. In assembly parameters, the seed fuel rod diameter has higher sensitivities to the conversion ratio (CR) than the coolant tube diameter in blanket. Increasing heavy metal fraction is good to CR improvement. The CR of SCFR also increases with a reasonable core arrangement and $P u$ isotope mass fraction reduction in fuel, which can achieve more negative coolant void reactivity coefficient at the same time. The breeding ratio of SCFR is $\mathbf{1 . 0 3 1 2 8}$ with a new core arrangement. And the coolant void reactivity coefficient is negative, which achieves a fuel breeding in initial fuel cycle.

\section{Keywords}

Supercritical Water Cooled Fast Reactor, Breeding Ratio, Coolant Void Coefficient

\section{Introduction}

Super-Critical Water-cooled Reactors (SCWRs) are a class of high temperature, high pressure, water-cooled reactors that operate above the thermodynamic critical point of water $\left(374^{\circ} \mathrm{C}, 22.1 \mathrm{MPa}\right)$. It has been developed as promisingly innovative candidate in the Generation IV Nuclear Reactor System of The GIF Technology Roadmap [1]. SCWR has several key technical advantages compared to conventional water technologies that make it attractive. The main thrusts of these advantages translate into improved economics because of the increased thermodynamic efficiency and plant simplification opportunities afforded by the high-temperature, sin-

${ }^{*}$ Corresponding author. 
gle-phase steam [2]. R\&D activities are carried out for the past decades. Numbers of conceptual design have been proposed both for thermal spectrum design [3]-[11], and fast spectrum concept [12]-[15].

Supercritical water-cooled fast reactor (SCFR) [16] is designed with MOX fuel and cooled by super-critical water. It is functioning with relatively higher neutron energy spectrum which requires less amount of moderation so that the core design is compact in size with higher power density $\left(294.8 \mathrm{~W} / \mathrm{cm}^{3}\right)$ and thermal efficiency (the coolant outlet temperature is $500^{\circ} \mathrm{C}$ ). Meanwhile, MOX fuel loading with flexible design of LWR spent fuel is available with a potential for closed fuel cycle and breeding [17].

In order to improve the breeding ratio of SCFR, abriquet fuel assembly is designed for increasing heavy metal fraction [18]. It means that coolant flows in tubes and the fuel is contained outside of the tubes; the positions of the fuel and the coolant are exchanged. The reactor power also increases with the briquet core. However, the coolant void reactivity coefficient of the core is positive. A tight lattice of the MOX fuel assembly in hexagonal geometry has been proposed with some blanket loaded in SCFR core design [15] [19]. The blanket assembly is to convert fertile nuclide and comprised of depleted $\mathrm{UO}_{2}$ fuel and $\mathrm{ZrH}_{1.7}$ layer as solid moderator. One notable characteristic and design challenge for SCFR is the possible positive void reactivity coefficient during the loss of coolant [20]. Blanket assembly is therefore capable of functioning not only to compensate the reactivity loss with burn-up but also to perform neutron absorption and moderation while the coolant is lost. But the conversion ratio (CR) of this design is less than 1 .

In this study, MCNP4C code is used to establish the SCFR physical model to study the effects of assembly parameters, fuel nuclide components and core arrangements on reactor conversion ratio(CR) and void reactivity coefficient in initial stage of the fuel cycle fuel (not involved burnup).

\section{Description of SCFR Core}

Yoo et al. [15] from Tokyo University had designed a high energy power SCFR core with a negative coolant void coefficient, the seed assemblies and the blanket assemblies are composite arranged in the core. In this study, SCFR-M (supercritical water-cooled fast reactor-mix layout) is designed on the basis of the conceptual design of SCFR which was proposed by Professor OKA. SCFR-M core is mixed layout within seed assembly and blanket assembly. In SCFR-M design, the neutron leakage from seed zone to blanket zone increasing by reducing stainless steel cladding thickness to strengthen fuel breeding. At the same time, through increasing the ZrH1.7 solid moderator layer thickness to deepen the negative void coefficient. Such design helps maintain a high energy power, and improve the fuel breeding and safety performance of the core.

The design of Seed assembly and blanket assembly is shown in Figure 1. Seed assembly consists of 312 fuel rods, 18 control rods and an instrumentation tube, MOX fuels are loaded, and the enrichment of ${ }^{235} \mathrm{U}^{2} \mathrm{UO}_{2}$ is $0.2 \%$. Pu isotopic composition is shown in Table 1. Blanket assembly consists of 217 breeding rods which filled with depleted uranium $\left({ }^{235} \mathrm{U}\right.$ mass fraction is $\left.0.2 \%\right)$. Assembly parameters are listed in Table 2.

The diameter and length of the core active region is $267 \mathrm{~cm}$ and $270 \mathrm{~cm}$ respectively. The top, bottom and outside parts of the core are water reflector regions (Figure 2). The main design parameters of the core are listed in Table 3. The core is cooled with a single phase water flow at a supercritical pressure of $25 \mathrm{MPa}$. The inlet coolant temperature of the reactor is $280^{\circ} \mathrm{C}$, the coolant from the hot leg is divided into two parts at the joint region of the main vessel and hot leg. Some of the coolant flows down and enters the vessel bottom chamber then,

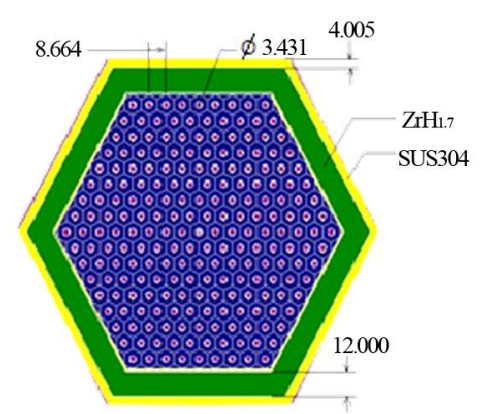

(a) blanket assembly

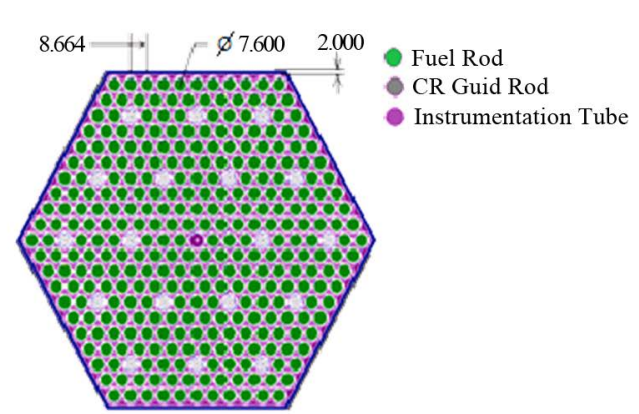

(b) seed assembly

Figure 1. SCFR-M assembly. 


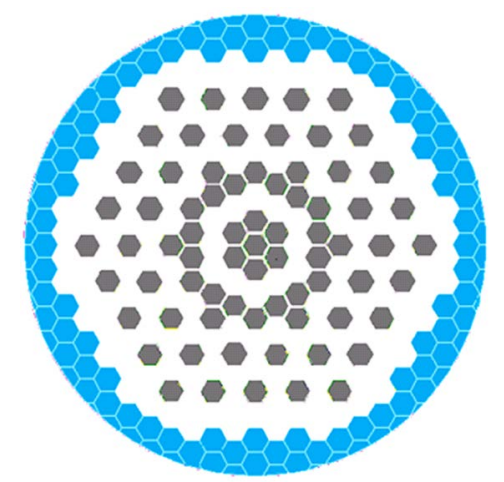

Figure 2. SCFR-M core.

Table 1. Pu isotopic composition in MOX.

\begin{tabular}{cccccc}
\hline Isotope & ${ }^{238} \mathrm{Pu}$ & ${ }^{239} \mathrm{Pu}$ & ${ }^{240} \mathrm{Pu}$ & ${ }^{241} \mathrm{Pu}$ & ${ }^{242} \mathrm{Pu}$ \\
\hline Mass fraction (\%) & 3.826 & 50.05 & 25.91 & 10.081 & 10.133 \\
\hline
\end{tabular}

Table 2. SCFR-M assembly parameters.

\begin{tabular}{|c|c|}
\hline Seed assembly & \\
\hline Fuel rod diameter $(\mathrm{mm}) /$ pitch $(\mathrm{mm}) / \mathrm{P} / \mathrm{D}$ & MOX 7.6/8.664/1.14 \\
\hline Fuel rod cladding material/thickness (mm) & SUS304/0.43 \\
\hline He gap (mm) & 0.05 \\
\hline Pu enrichment & $21.3 \%, 20.8 \%, 20.2 \%, 19.6 \%$ \\
\hline Fuel rod number & 312 \\
\hline Assembly cladding material/thickness (mm) & SUS304/2 \\
\hline \multicolumn{2}{|l|}{ Blanket assembly } \\
\hline Water rod diameter $(\mathrm{mm}) /$ pitch $(\mathrm{mm}) / \mathrm{P} / \mathrm{D}$ & $3.431 / 8.664 / 2.525$ \\
\hline Cladding material/thickness (mm) & SUS304/0.25 \\
\hline Fertile material & Depleted uranium $\left({ }^{235} \mathrm{U} 0.2 \%{ }^{238} \mathrm{U} 99.8 \%\right)$ \\
\hline Blanket rod number & 217 \\
\hline Solid moderator/thickness (mm) & $\mathrm{ZrH}_{1.7} / 12$ \\
\hline Stainless steel cladding thickness (mm) & 4.005 \\
\hline Assembly cladding material/thickness (mm) & SUS304/1 \\
\hline
\end{tabular}

Table 3. Design parameters of SCFR-M.

\begin{tabular}{cc} 
Core parameters & Value \\
\hline Core thermal power (MWt) & 2358 \\
Core electric power (MWe) & 1033 \\
Equivalent core diameter $(\mathrm{cm})$ & 267 \\
Active core height $(\mathrm{cm})$ & 270 \\
Seed assembly & 162 \\
Blanket assembly & 73 \\
Fission Pu enrichment $(\mathrm{wt} \%)$ & $20.8 \%$ \\
Core inlet/outlet temperature $\left({ }^{\circ} \mathrm{C}\right)$ & $280 / 503$ \\
\hline
\end{tabular}


the other part of the coolant flows upward to the vessel upper plenum and then down through the core blanket assemblies with the temperature rise is $49^{\circ} \mathrm{C}$. The two parts of the coolant mixing in the vessel bottom chamber and the average coolant temperature is $304^{\circ} \mathrm{C}$. Then, the mixed coolant flows upward and heated by the seed assembly, the average outlet temperature is about $503^{\circ} \mathrm{C}$. The circulation of the coolant in the primary cooling system is shown in Figure 3. In SCFR, the coolant density changes greatly in the axial direction of the core $\left(0.089-0.78 \mathrm{~g} / \mathrm{cm}^{3}\right)$. The Pu enrichment of the seed assembly is shown in Figure 4. In order to flatten the radial power of the core, the active region of the seed fuel assembly is divided into four regions in axial direction; each region is filled with different Pu mass fraction of MOX fuel.

In MCNP4C cross section library, only some important actinides and the moderator nuclide has cross section at different temperature, which can not satisfy reactor neutronics calculation under various temperature conditions. Therefore, a multi-temperature continuous point cross section library produced by NJOY99 code is necessary. The self-made multi-temperature continuous point cross section library is used to SCFR neutronics calculation, the fuel pellet temperature is $1200 \mathrm{~K}$, the coolant temperature is $600 \mathrm{~K}$. In MCNP4C computing model, the number of particles is 60,000 , the number of iterations is 250 , the first 50 times are ignored.

\section{The Effect of Assembly Parameters on CR}

In SCFR, the main nuclear fuel cycle is the U-Pu cycle, ${ }^{235} \mathrm{U},{ }^{239} \mathrm{Pu},{ }^{241} \mathrm{Pu}$ are fissile materials, ${ }^{238} \mathrm{U}$, ${ }^{240} \mathrm{Puare}$ convertible materials. After (n, $\gamma$ ) reaction and the $\beta$ decay, ${ }^{238} \mathrm{U}$ converted to ${ }^{239} \mathrm{Pu}$, and ${ }^{240} \mathrm{Pu}$ converted to ${ }^{241} \mathrm{Pu}$ by $(\mathrm{n}, \gamma)$ reaction. The main fissile nuclides by the following reaction achieve nuclear breeding.

$$
\begin{gathered}
{ }^{238} \mathrm{U} \stackrel{(n, r)}{\longrightarrow}{ }^{239} \mathrm{U} \stackrel{\beta^{-}(23 \min )}{\longrightarrow}{ }^{239} \mathrm{~Np} \stackrel{\beta^{-}(2.3 d)}{\longrightarrow}{ }^{239} \mathrm{Pu} \\
{ }^{240} \mathrm{Pu} \stackrel{(n, y)}{\longrightarrow}{ }^{241} \mathrm{Pu}
\end{gathered}
$$

CR is generally defined as the consumption of a fissile material atom to produce new fissile material atoms, namely:

$$
\mathrm{CR}=\frac{\text { fissile nuclides production rate }}{\text { fissile nuclides consumption rate }}=\frac{\text { convertible nuclides capture rate }}{\text { fissile nuclides absorption rate }}
$$

It's worth noting that, all of the above reaction rates involved are obtained from the MCNP4C calculation of the initial stage of the fuel cycle.

When the core coolant produce vacuoles, the neutron spectrum hardening, the ${ }^{239} \mathrm{Pu}$ resonance fission and the ${ }^{238} \mathrm{U}$ threshold fission increase, SCFR core tends to a positive void reactivity coefficient [21]. Therefore, the void reactivity should be considering in research.

The volume percentage of vapor bubbles in coolant is void fraction, represented by $x$. The void reactivity coefficient refers to reactivity change caused by one percent change in void fraction, represented by $a_{V}^{M}$. This is,

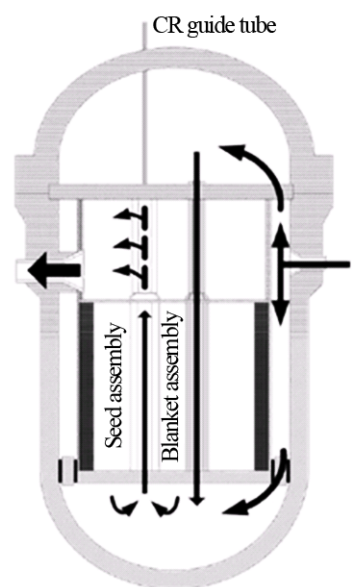

Figure 3. Pu enrichment of the seed assembly. 


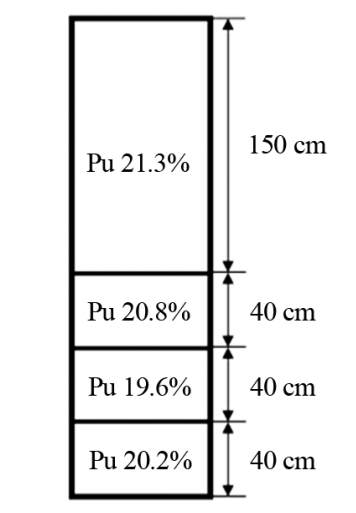

Figure 4. Coolant flow chart.

$$
a_{V}^{M}=\frac{\partial \rho}{\partial x}
$$

The CR of SCFR-M is depended on the Hydrogenatoms/Heavy Metal atoms (H/HM) and fertile fuel volume fraction [3]. The diameter of seed rod has a great impact on the H/HM. The calculation results of $K_{\text {eff, }}$ CR and void reactivity coefficient with different pitch shown in Table 4.

As is shown in Table 4, maintaining the same assembly size, with the increasing of the fuel rod diameter, the $\mathrm{P} / \mathrm{D}$ decreases and the $K_{\text {eff }}$ increases. At the same time, the fuel conversion ratio grows. In all cases, the core void reactivity coefficients are negative. From the calculated results, we know that improving the conversion ratio of fuel must reduce H/HM. Therefore, the design of seed assembly take a compact arrangement of pin cell, a larger diameter fuel rods or narrow fuel rod gap to reduce the volume of coolant are feasible.

As is shown in Table 4, with the coolant tube diameter narrowing, the volume fraction of fertile material enhances and the $K_{\text {eff }}$ of core grows and conversion ratio also improves, all the void reactivity coefficients are negative. Finally, combining the results of Table 3 and Table 4, fuel rod diameter in seed have greater impact on conversion ratio than the coolant tube diameter in blanket. The coolant tubes diameter directly affects number of hydrogen atoms and H/HM. The reason for high sensitivity of seed fuelrods is that the consumption of fissile plutonium becomes lower with the increase of seed fuel rod diameters.

\section{The Effect of Core Arrangement on CR}

From above calculation results, we can see that the CR in all the cases are less than 1, the core can't proliferate. So we propose 5 improved core arrangement which illustrated in Figure 5, and compare the CR and void reactivity coefficient with the initial core arrangement (assembly parameters are shown in Table 2), the results are shown in Table 5.

Table 6 shows that, keeping the seed assembly quantity unchanged, increasing the number of blanket assembly can improve CR. Keeping the total assembly same, raising $\mathrm{N}_{\text {blanket }} / \mathrm{N}_{\text {seed }}$ can also achieve the goal.

The CR of case 3, case 4, case 5 and case 6 are above 1, but the void reactivity coefficient of case 4 is positive. Comprehensive consideration of CR, void reactivity coefficient and fuel breeding efficiency, case 6 is chosen for further study finally, to make analysis of the impact factors on CR.

\section{The Effect of Fuel Nuclide Components on CR}

Figure 6 and Figure 7 are the CR varies with the changes of fuel nuclides component. From Figure 6, making the fuel enrichment of seed fixed, changing the ${ }^{235} \mathrm{U}$ enrichment of blanket assembly, CR decreases with the increasing of ${ }^{235} \mathrm{U}$ enrichment. From Figure 7, maintaining the fuel enrichment of blanket fixed and changing the ${ }^{239} \mathrm{Pu}$ isotope mass fraction of seed assembly, when the ${ }^{239}$ Puisotope mass fraction increases, the CR shows a linear reduction. Therefore, adjustment of the fuel enrichment is more significant than changing the structure of assembly for improving CR.

Figure 8 and Figure 9 are the void reactivity varies with the changes of fuel nuclide component. It can be seen that changing the enrichment of ${ }^{235} \mathrm{U}$ in blanket assembly have a little effect on void reactivity, while the 
Table 4. Calculation results of fuel rods with different diameter.

\begin{tabular}{ccccc}
\hline Fuel rod diameter $/ \mathrm{m}^{\mathrm{a}}$ & $\mathrm{P} / \mathrm{D}$ & $K_{\text {eff }}$ & CR & Void reactivity \\
\hline 0.6916 & 1.10 & 1.05222 & 0.85686 & Negative \\
0.6640 & 1.14 & 1.03936 & 0.85289 & Negative \\
0.6380 & 1.18 & 1.02513 & 0.85023 & Negative \\
0.6140 & 1.22 & 1.01599 & 0.84795 & Negative \\
0.5916 & 1.26 & 1.00457 & 0.84419 & Negative \\
\hline
\end{tabular}

a Blanket assembly use Table 2 data.

Table 5. Calculation results of different core arrangement.

\begin{tabular}{ccccccc}
\hline Core arrangement & $\begin{array}{c}\text { Total assembly } \\
\text { number }\end{array}$ & Blanket assembly number & Seed assembly number & $K_{\text {eff }}$ & CR & Void reactivity coefficient \\
\hline 1 & 235 & 73 & 162 & 1.03936 & 0.85289 & Negative \\
2 & 235 & 85 & 150 & 1.01971 & 0.94153 & Negative \\
3 & 235 & 97 & 138 & 1.00799 & 1.02068 & Negative \\
4 & 235 & 90 & 145 & 1.02886 & 1.00190 & Positive \\
5 & 253 & 108 & 145 & 0.97538 & 1.10289 & Negative \\
6 & 253 & 103 & 150 & 1.02485 & 1.04395 & Negative \\
\hline
\end{tabular}

Table 6. Calculation results of blanket coolant tubes with different diameter.

\begin{tabular}{ccccc}
\hline Coolant tubes diameters $/ \mathrm{cm}^{\mathrm{b}}$ & P/D & $K_{\text {eff }}$ & CR & Void reactivity \\
\hline 0.42785 & 2.025 & 1.03474 & 0.84770 & Negative \\
0.38084 & 2.275 & 1.03607 & 0.85203 & Negative \\
0.36024 & 2.405 & 1.03688 & 0.85274 & Negative \\
0.34312 & 2.525 & 1.03936 & 0.85289 & Negative \\
0.31222 & 2.775 & 1.03855 & 0.85720 & Negative \\
\hline
\end{tabular}

${ }^{\mathrm{b}}$ Seed assembly use Table 2 data.

adjustment of ${ }^{239} \mathrm{Pu}$ have more effects. The Void reactivity of different fuel nuclide components are listed in Table 7. Form Table 7, we can see that, with the increase of ${ }^{235} \mathrm{U}$ enrichment in blanket assembly, the negative void coefficient dropped slightly. When Pu isotope mass fraction increasing, the core's neutron energy spectrum hardening. This leads to the resonance fission of ${ }^{239} \mathrm{Pu}$ and the threshold fission of ${ }^{238} \mathrm{U}$ growing, core tend to a positive void reactivity coefficient. Therefore, reduce Pu isotope mass fraction is an effective method to increase CR and ensure the negative coolant void reactivity.

\section{SCFR-M Physical Properties}

Case 6 is selected as core arrangement for studying the neutronics performance. In the first fuel cycle, the different enrichment seed assemblies are loaded into the core of 3 zones, as show in Figure 10. The core active height increased from $270 \mathrm{~cm}$ to $320 \mathrm{~cm}$ to reduce the peak liner heat rate. The radial fuel loaded zone shown in Figure 5 and Pu mass fractions of three kinds of seed assemblies are listed in Table 8.

A critical neutronics calculation of the reactor core has been carried out by MCNP4C code, the results as follow: $K_{\text {eff }}=1.02691 \pm 0.00058$, CR $=1.03128$. The CR of core designed by Yoo et al. [15] is 0.696. Thus, the optimized assembly design and reasonable core arrangement significantly improve the CR. The effective delayed-neutron fraction $\beta_{\text {eff }}=0.42510 \%$, which is less than PWR (the $\beta_{\text {eff }}$ of PWR is $0.65 \%$ ), because of ${ }^{239} \mathrm{Pu}$ 's effective delayed-neutron fraction is less than ${ }^{235} \mathrm{U}$.

The core power distribution of SCFR-M is shown in Figure 11. The power of seed zone is calculated as 2040 


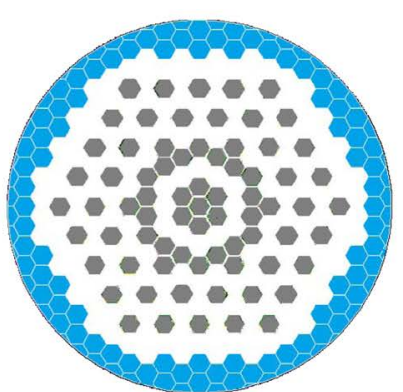

(a) Core 1(initial SCFR)

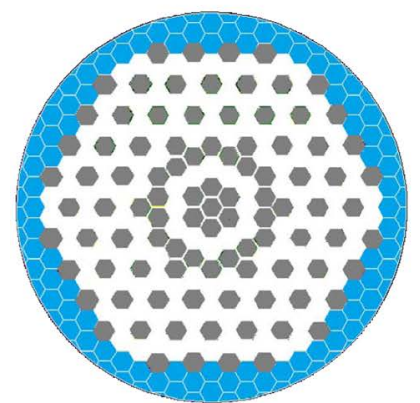

(c) Core 3

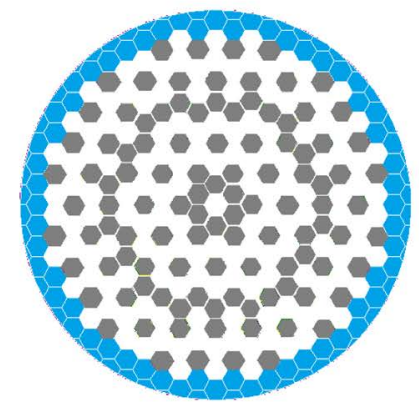

(e) Core 5

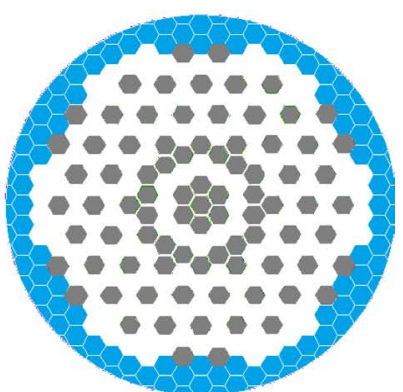

(b) Core 2

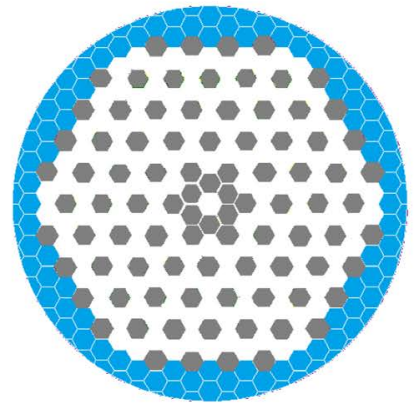

(d) Core4

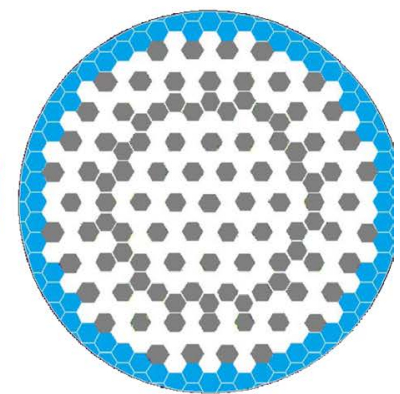

(f) Core6

Figure 5. Improved core arrangement.

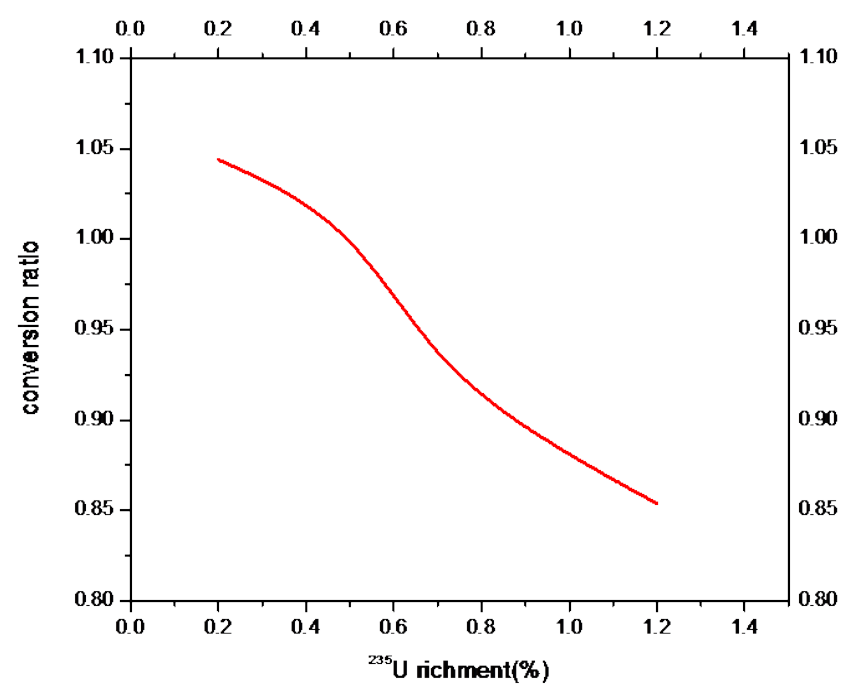

Figure 6. CR of blanket assembly with different ${ }^{235} \mathrm{U}$ enrichment (fuel enrichment of seed is fixed). 


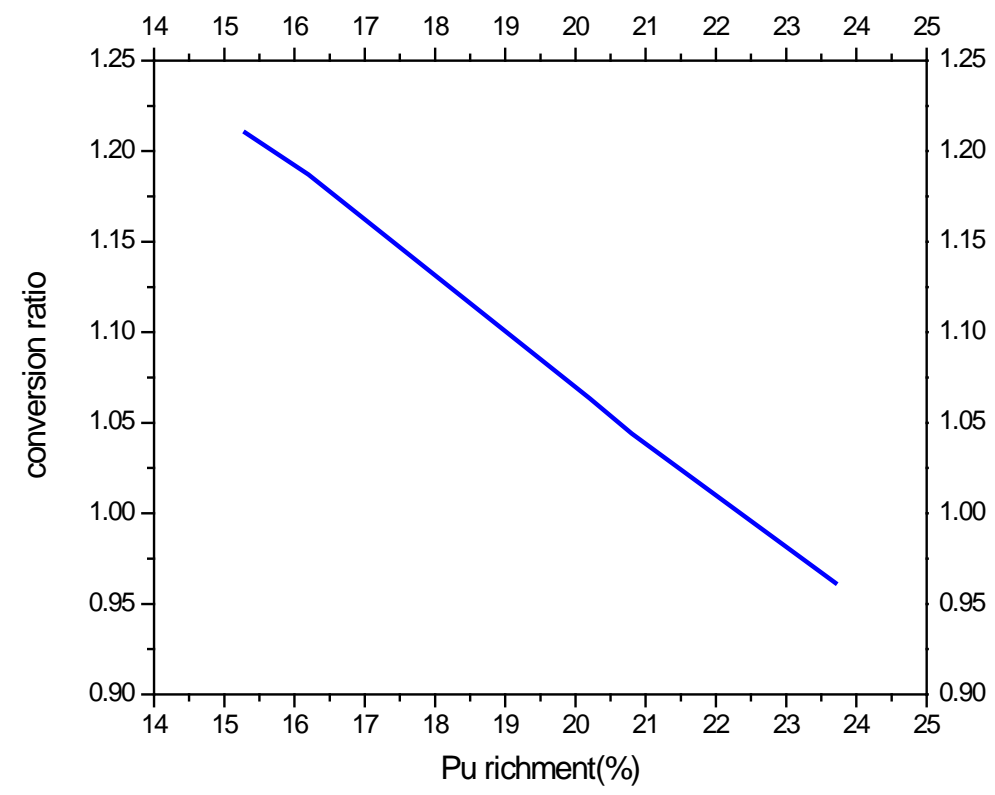

Figure 7. CR of seed assembly with different ${ }^{239} \mathrm{Pu}$ isotope mass fraction (fuel enrichment of blanket is fixed).

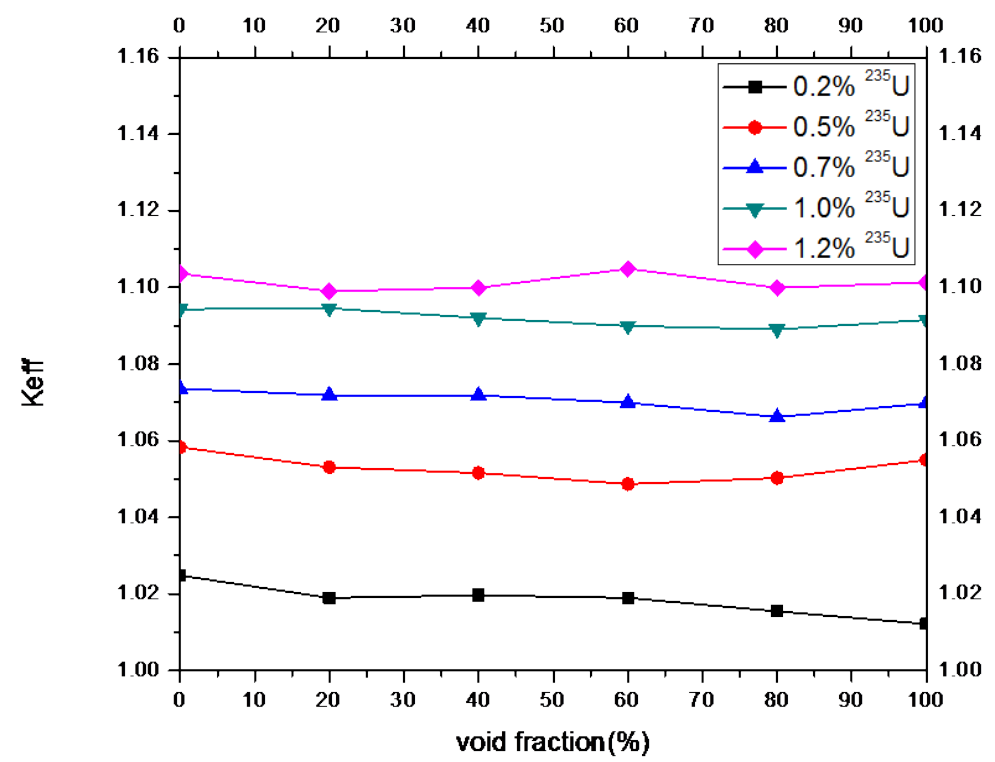

Figure 8. $K_{\text {eff }}$ changes with void fractions for different ${ }^{235} U$ enrichments in blanket assembly.

Table 7. Void reactivity of different fuel nuclide components.

\begin{tabular}{|c|c|c|c|c|c|}
\hline $\begin{array}{l}{ }^{235} \mathrm{U} \text { enrichment in blanket assembly } \\
\text { (Pu isotope mass fraction in seed assembly is 20.8\%) }\end{array}$ & $0.2 \%$ & $0.5 \%$ & $0.7 \%$ & $1.0 \%$ & $1.2 \%$ \\
\hline $\begin{array}{l}\text { Reactivity difference between no vacuole } \\
\text { and completely vacuoles (pcm) }\end{array}$ & -1223 & -305 & -334 & -236 & -187 \\
\hline $\begin{array}{l}\mathrm{Pu} \text { isotope mass fraction in seed assembly } \\
\left({ }^{235} \mathrm{U} \text { enrichment in seed assembly is } 0.2 \%\right)\end{array}$ & $15.3 \%$ & $16.2 \%$ & $20.2 \%$ & $20.8 \%$ & $23.7 \%$ \\
\hline $\begin{array}{l}\text { Reactivity difference between no vacuole } \\
\text { and completely vacuoles (pcm) }\end{array}$ & -2702 & -2338 & -915 & -1223 & 86 \\
\hline
\end{tabular}




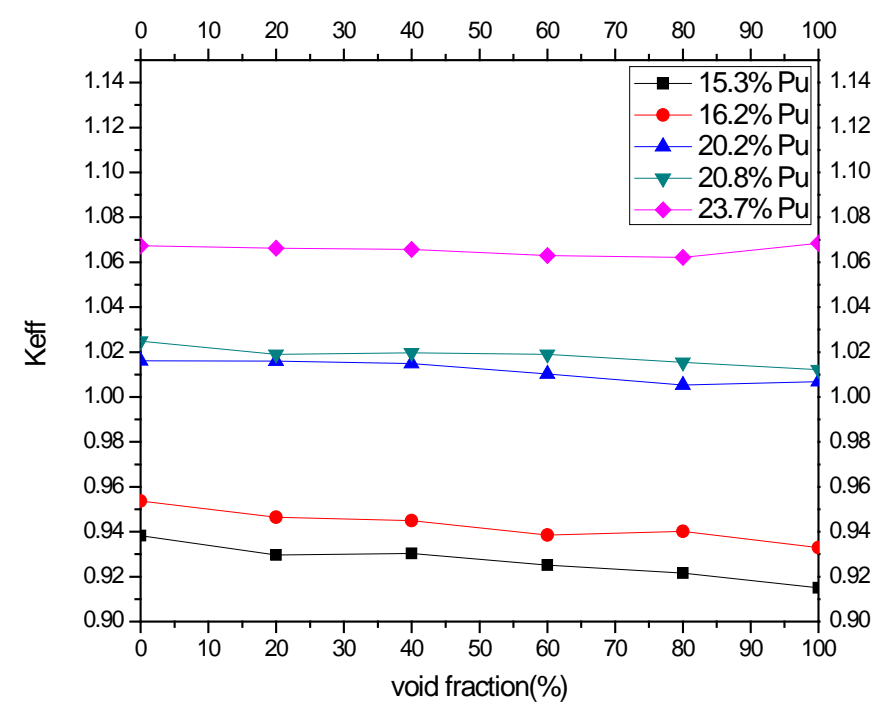

Figure 9. $K_{\text {eff }}$ changes with void fractions for different ${ }^{239} \mathrm{Pu}$ isotope mass fraction in seed assembly.

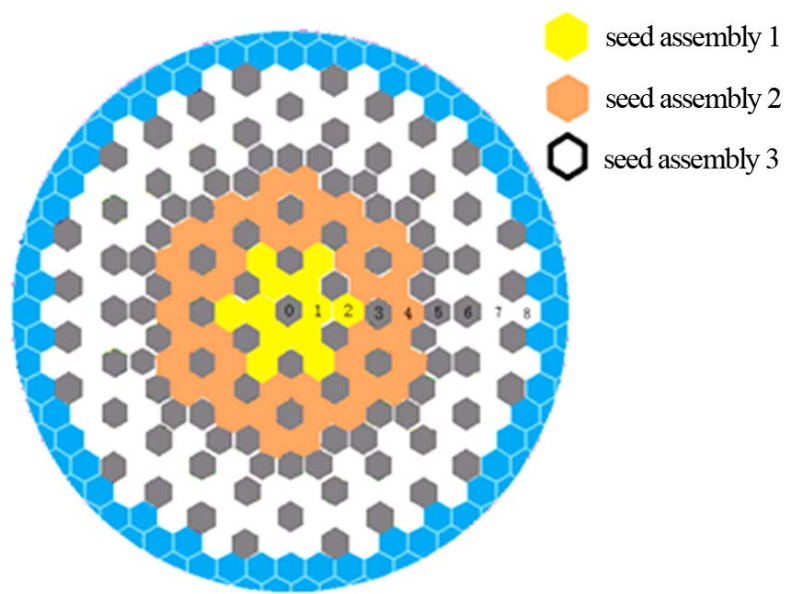

Figure 10. Radial fuel enrichment zone in the core.

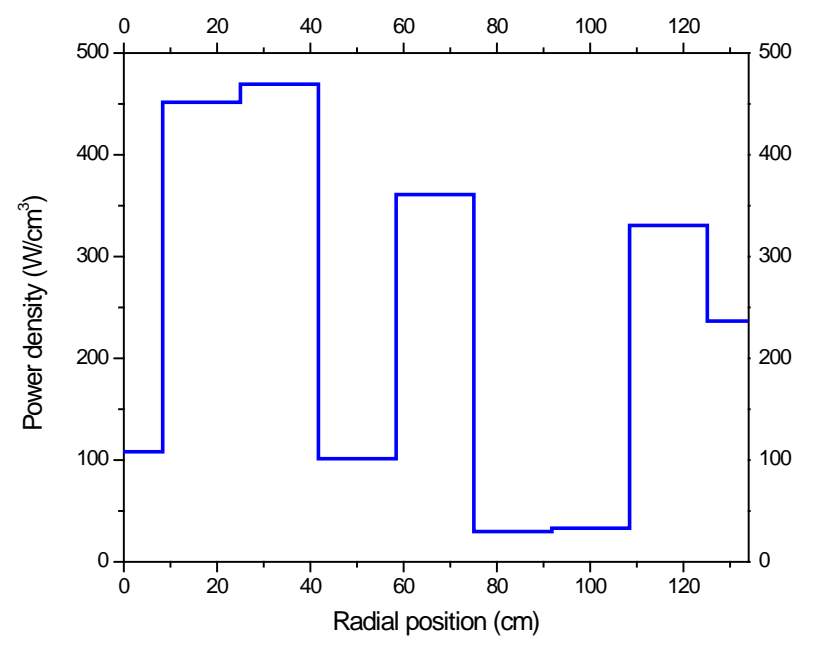

Figure 11. Core power distribution of SCFR-M. 


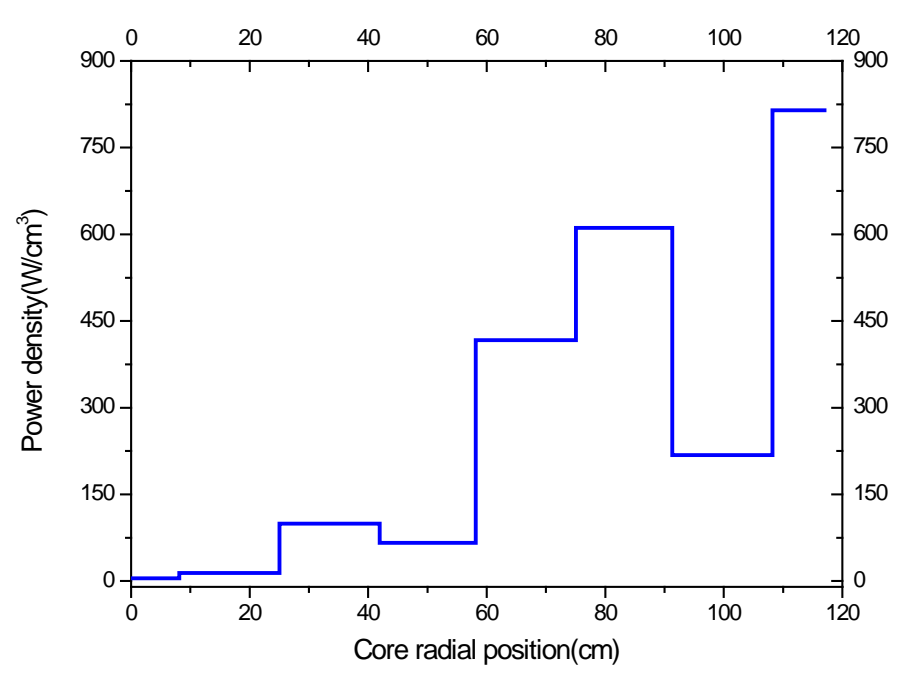

Figure 12. Core power distribution of SCFR designed by Yoo et al. [15].

Table 8. Pu mass fractions in seed assembly.

\begin{tabular}{cccc}
\hline Zone & Seed assembly 1 & Seed assembly 2 & Seed assembly 3 \\
\hline $0-50 \mathrm{~cm}$ & $15.01 \%$ & $20.2 \%$ & $24.25 \%$ \\
$50-100 \mathrm{~cm}$ & $14.43 \%$ & $19.6 \%$ & $23.67 \%$ \\
$100-150 \mathrm{~cm}$ & $15.59 \%$ & $20.8 \%$ & $24.9 \%$ \\
$150-320 \mathrm{~cm}$ & $16.17 \%$ & $21.3 \%$ & $25.5 \%$ \\
\hline
\end{tabular}

MW, the average power density of the active region is $393.36 \mathrm{~W} / \mathrm{cm}^{3}$; the power of blanket zone is $306 \mathrm{MW}$, the average power density of the active region is $78.06 \mathrm{~W} / \mathrm{cm}^{3}$. The total power of reactor core is $2346 \mathrm{MW}$; the average power density is $130.88 \mathrm{~W} / \mathrm{cm}^{3}$. Most of energy generated by the seed zone, blanket zone energy is less, therefore, the core radial power density distribution of high and low present columnar shapes. However, the power distribution of seed assembly is relatively uniform, and the ratio of the maximum to the average power density of seed assembly is 1.19. Compared with SCFR designed by Yoo et al. (Figure 12), the power distribution has been greatly improved.

Moreover, the temperature of fuel pellets, coolant and fuel cladding have been calculated by CFD code Fluent. As shown in Figure 13 and Table 9, the maximum temperature of fuel pellets is $1230^{\circ} \mathrm{C}$; the coolant and the cladding temperature is gradually increased up from the bottom of core; the maximum cladding temperature is $629^{\circ} \mathrm{C}$, which meets the design criteria requirement of the maximum fuel cladding temperature not exceeding $650^{\circ} \mathrm{C}$. And another design criterion is that the void coefficient is negative. Therefore, the SCFR-M consistent with safety design limits.

\section{Conclusions}

In this paper, aiming at enhancing CR of core, the improved SCFR assembly has been proposed. The effects of assembly parameters, core arrangement and fuel component on breeding ratio and void reactivity of SCFR-M have been analyzed as well. Following conclusions are obtained: CR can be increased by increasing the fuel rod diameter or reducing the coolant tube diameter of seed and blanket assembly respectively; however, fuel rod diameter of seed has a greater impact on CR.

More negative void reactivity and higher CR can be obtained by increasing blanket assembly quantity and adopting a reasonable core arrangement. Reduction of the Pu isotopes mass fraction in the fuel can significantly improve CR and obtain a smaller void reactivity coefficient.

With the above research, we can acquire the following conclusions: The Pu isotope mass fraction in MOX 


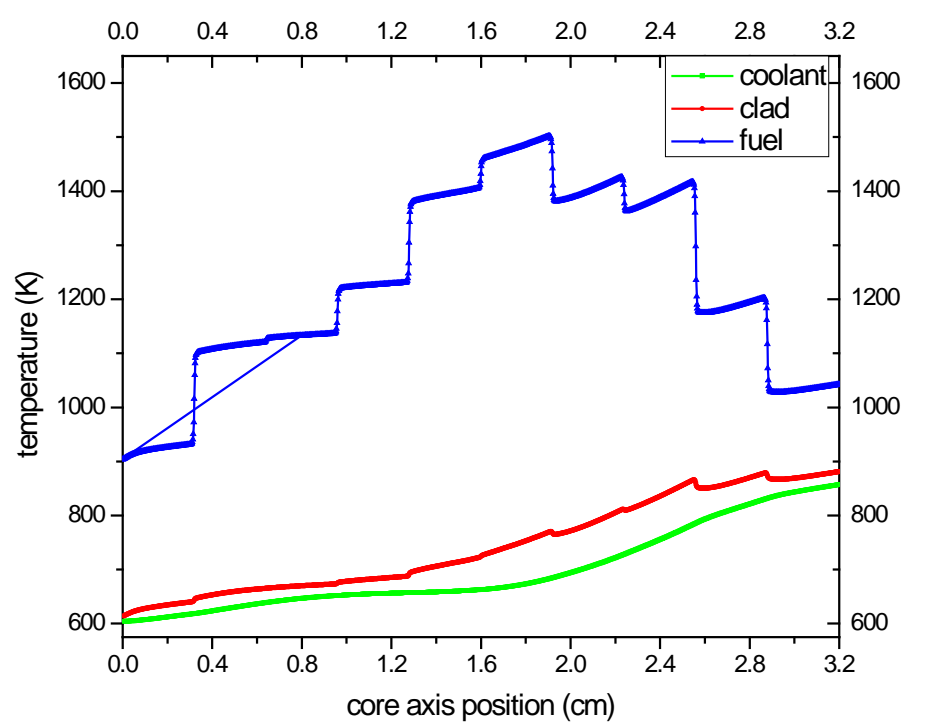

Figure 13. Coolant, fuel and cladding temperature in seed assembly.

Table 9. Final SCFR-M core parameters.

\begin{tabular}{cc}
\hline Parameter & Data \\
\hline Core thermal power/MW & 2340 \\
Core active diameter $/ \mathrm{cm}$ & 267 \\
Core active height/cm & 320 \\
Seed assembly quantity & 150 \\
Blanket assembly quantity & 103 \\
Average Pu enrichment $/ \%$ & 20.8 \\
Core inlet $/$ outlet temperature $/{ }^{\circ} \mathrm{C}$ & 280,503 \\
Coolant outlet flow $/ \mathrm{kg} / \mathrm{m}^{3}$ & 105 \\
Maximum cladding temperature $/{ }^{\circ} \mathrm{C}$ & 629 \\
Average power density $/ \mathrm{W} / \mathrm{cm}^{3}$ & 131 \\
Coolant void reactivity $/ \% \Delta \mathrm{k} / \mathrm{k}$ & -1.36
\end{tabular}

fuel is 20.8\%; filled with depleted uranium in the blanket assembly, enrichment of ${ }^{235} \mathrm{U}$ is $0.2 \%$. In the case 6 of core arrangement, the CR of core can reach 1.03128; the void reactivity coefficient is negative; and maximum cladding temperature is $629^{\circ} \mathrm{C}$, which achieves the requirements of a preliminary breeding SCFR.

\section{References}

[1] Schulenberg, T., Leung, L.K.H. and Oka, Y. (2014) Review of R\&D for Supercritical Water Cooled Reactors. Progress in Nuclear Energy, 77, 282-299. http://dx.doi.org/10.1016/j.pnucene.2014.02.021

[2] Cheng, X., Schulenberg, T., Bittermann, D., et al. (2003) Design Analysis of Core Assemblies for Supercritical Pressure Conditions. Nuclear Engineering and Design, 223, 279-294. http://dx.doi.org/10.1016/S0029-5493(03)00059-1

[3] Cheng, X., Liu, X.J. and Yang, Y.H. (2008) A Mixed Core for Supercritical Water-Cooled Reactors. Nuclear Engineering and Technology, 40, 117-126. http://dx.doi.org/10.5516/NET.2008.40.2.117

[4] Dobashi, K., Kimura, A., Oka, Y., et al. (1998) Conceptual Design of a High Temperature Power Reactor Cooled and Moderated by Supercritical Light Water. Annals of Nuclear Energy, 25, 487-505. http://dx.doi.org/10.1016/S0306-4549(97)00079-0

[5] Kamei, K., Yamaji, A., Ishiwatari, Y., et al. (2006) Fuel and Core Design of Super Light Water Reactor with Low 
Leakage Fuel Loading Pattern. Journal of Nuclear Science and Technology, 43, 129-139. http://dx.doi.org/10.1080/18811248.2006.9711075

[6] Liu, X.J. and Cheng, X. (2009) Thermal-Hydraulic and Neutron-Physical Characteristics of a New SCWR Fuel Assembly. Annals of Nuclear Energy, 36, 28-36. http://dx.doi.org/10.1016/j.anucene.2008.11.001

[7] Okano, Y., Koshizuka, S. and Oka, Y. (1994) Design of Water Rod Cores of a Direct Cycle Supercritical-Pressure Light Water Reactor. Annals of Nuclear Energy, 21, 601-611. http://dx.doi.org/10.1016/0306-4549(94)90070-1

[8] Okano, Y., Koshizuka, S. and Oka, Y. (1996) Core Design of a Direct-Cycle, Supercritical-Pressure, Light Water Reactor with Double Tube Water rods. Journal of Nuclear Science and Technology, 33, 365-373. http://dx.doi.org/10.1080/18811248.1996.9731920

[9] Yamaji, A., Kamei, K., Oka, Y., et al. (2005) Improved Core Design of the High Temperature Supercritical-Pressure Light Water Reactor. Annals of Nuclear Energy, 32, 651-670. http://dx.doi.org/10.1016/j.anucene.2004.12.006

[10] Yamaji, A., Oka, Y. and Koshizuka, S. (2005) Three-Dimensional Core Design of High Temperature SupercriticalPressure Light Water Reactor with Neutronic and Thermal-Hydraulic Coupling. Journal of Nuclear Science and Technology, 42, 8-19. http://dx.doi.org/10.1080/18811248.2005.9726359

[11] Yang, P., Cao, L., Wu, H., et al. (2011) Core Design Study on CANDU-SCWR with 3D Neutronics/Thermal-Hydraulics Coupling. Nuclear Engineering and Design, 241, 4714-4719. http://dx.doi.org/10.1016/j.nucengdes.2011.03.036

[12] Jevremovic, T., Oka, Y. and Koshizuka, S. (1993) Design of an Indirect-Cycle Fast Breeder Reactor Cooled by Supercritical Steam. Nuclear Engineering and Design, 144, 337-344. http://dx.doi.org/10.1016/0029-5493(93)90149-4

[13] Jevremovic, T., Oka, Y. and Koshizuka, S.I. (1994) Core Design of a Direct-Cycle, Supercritical-Water-Cooled Fast Breeder Reactor. Nuclear Technology, 108, 24-32.

[14] Mukohara, T., Koshizuka, S.I. and Oka, Y. (1999) Core Design of a High-Temperature Fast Reactor Cooled by Supercritical Light Water. Annals of Nuclear Energy, 26, 1423-1436. http://dx.doi.org/10.1016/S0306-4549(99)00032-8

[15] Yoo, J., Ishiwatari, Y., Oka, Y., et al. (2006) Conceptual Design of Compact Supercritical Water-Cooled Fast Reactor with Thermal Hydraulic Coupling. Annals of Nuclear Energy, 33, 945-956.

[16] Oka, Y., Koshizuka, S., Ishiwatari, Y., et al. (2010) Super Light Water Reactors and Super Fast Reactors: Supercritical-Pressure Light Water Cooled Reactors. Springer Science \& Business Media, New York. http://dx.doi.org/10.1007/978-1-4419-6035-1

[17] Liu, Q. and Oka, Y. (2013) Core Design for Super Fast Reactor with All Upward Flow Core Cooling. Annals of Nuclear Energy, 57, 221-229. http://dx.doi.org/10.1016/j.anucene.2013.01.058

[18] Ishiwatari, Y., Oka, Y. and Koshizuka, S. (2001) Breeding Ratio Analysis of a Fast Reactor Cooled by Supercritical Light Water. Journal of Nuclear Science and Technology, 38, 703-710. http://dx.doi.org/10.1080/18811248.2001.9715086

[19] Cao, L., Oka, Y., Ishiwatari, Y., et al. (2008) Fuel, Core Design and Subchannel Analysis of a Superfast Reactor. Journal of Nuclear Science and Technology, 45, 138-148. http://dx.doi.org/10.1080/18811248.2008.9711423

[20] Oka, Y. and Jevremovic, T. (1996) Negative Coolant Void Reactivity in Large Fast Breeder Reactors with Hydrogenous Moderator Layer. Annals of Nuclear Energy, 23, 1105-1115. http://dx.doi.org/10.1016/0306-4549(95)00117-4

[21] Mori, M., Maschek, W. and Rineiski, A. (2006) Heterogeneous Cores for Improved Safety Performance-A Case Study: The Super Critical Water Fast Reactor. Nuclear Engineering and Design, 236, 1573-1579.

http://dx.doi.org/10.1016/j.nucengdes.2006.03.048 